\title{
Review
}

\section{Contrast Nephropathy}

Shereif H. Rezkalla, MD, Department of Cardiology, Marshfield Cinic, Marshfield, Wisconsin

\begin{abstract}
Contrast nephropathy will increase mortality up to 30\% following angiographic procedures. Before performing such procedures a careful reassessment of the risk/benefit ratio should be performed. Mannitol and diuretics play no role in prevention. Hydration and correction of abnormal electrolyte levels should be done in all patients. Pre-treatment with acetylcysteine and theophylline is a well-accepted strategy and should always be utilized. If creatinine levels are above 2.5 to $3 \mathrm{mg} / \mathrm{dl}$, fenoldopam may provide additional protection, particularly in diabetic patients. However, the role of fenoldopam is controversial. Prophylactic hemodialysis may prove to be an additional tool in the fight against this disease in selected patients.
\end{abstract}

\section{INTRODUCTION}

Contrast nephropathy is defined as a rise in the serum creatinine level of at least $0.5 \mathrm{mg} / \mathrm{dl}$ within 48 hours of contrast medium administration. ${ }^{1}$ While this is the most accepted definition, other definitions are cited, such as an increase in serum creatinine of more than $25 \%$ of the baseline level within 48 hours of administration of the contrast agent.

The incidence of contrast nephropathy is variable and ranges from $5 \%$ to $50 \%$ in various series. The lower incidence is observed in patients with mild renal dysfunction. Patients with creatinine $>1.3 \mathrm{mg} / \mathrm{dll}$, dehydration, diabetes mellitus and the concomitant use of nephrotoxic medications will have a higher incidence. With a higher dose of the contrast medium, the frequency of toxicity will be higher. Serious nephrotoxicity requiring dialysis, however, is rare and occurs in $<1 \%$ of patients. In the era of modern interventional cardiology, many patients require multiple angiographic procedures during their lifetime. Any worsening in kidney function will render the patient even more vulnerable to further deterioration with future procedures.

REPRINT REQUESTS:

Shereif H. Rezkalla, MD

Department of Cardiology

Marshfield Clinic

1000 North Oak Avenue

Marshfield, WI 54449

Telephone: 715-387-5301

Fax: 715-389-3808

Email: rezkalla.shereif@marshfieldclinic.org
KEYWORDS:

Contrast nephropathy; Angiography; Acetylcysteine 
Various degrees of renal dysfunction are frequently encountered in patients undergoing coronary angiography and other diagnostic procedures that utilize various radiographic contrast agents. The association is not by chance alone, for some risk factors that contribute to coronary artery disease are also frequently implicated in renal vascular disease. Patients undergoing coronary angiography frequently have concomitant renal artery stenosis. ${ }^{2}$ Mild renal insufficiency is one independent predictor of the presence of significant coronary artery disease. ${ }^{3}$ With the worsening of renal insufficiency in patients undergoing angiography, it is not surprising that such patients will have a poor prognosis. Hemmelgarn et al. followed 16,989 patients undergoing coronary angiography for 1 year. ${ }^{4}$ Those patients who were undergoing kidney dialysis had a mortality of $15 \%$, patients with serum creatinine levels $>2.3 \mathrm{mg} / \mathrm{dl}$ had a mortality of $30 \%$, while a mortality of $4 \%$ was found in patients with a creatinine level $<2.3 \mathrm{mg} / \mathrm{dl}$. This poor prognosis was found in other studies as well.5,6 Such a clinical impact, coupled with the fact that patients with renal insufficiency are likely to require more than an angiographic procedure, urges clinicians to spare no effort to try to prevent or lessen contrast nephropathy. Mechanisms of contrast nephropathy, and various techniques and medications utilized to achieve such a goal will be discussed.

Contrast agents will lead to an increase in osmolality. These increases may reflexively cause vasoconstriction of the afferent arterioles and subsequently medullary ischemia. These effects may be caused by calcium channels and are mediated by adenosine release. The ischemia will likely cause damage to the kidney, and that damage is mediated by oxygen free radicals. ${ }^{7}$ It is also suggested that contrast agents may have a direct toxic effect on the kidney, which may also be mediated through the production of oxygen free radicals. Occasionally an atheroembolus may be dislodged into the renal arteries during invasive angiography procedures, leading to renal dysfunction indistinguishable from contrast nephropathy (figure 1).

\section{PREVENTION OF CONTRAST NEPHROPATHY}

The first step in the prevention of contrast nephropathy is the careful calculation of the risk/benefit ratio prior to performing the procedure. This is of importance in patients with higher serum creatinine levels, particularly when there is concomitant diabetes, as they are the patients with the highest risk for the disease. ${ }^{8}$ Patients need to be well hydrated. Isotonic hydration is superior to half normal saline. ${ }^{9}$ Patients also need to have normal electrolyte levels and since hypomagnesemia increases the incidence of contrast nephropathy, magnesium levels should be normalized as well. ${ }^{7}$ Although the new low osmolar contrast agents are not routinely used in all patients due to their exorbitant cost, they should be utilized in patients with higher serum creatine levels. ${ }^{8}$

The most important variable of the angiographic procedure is to use as little dye as possible. To achieve this, if at all possible, avoid left ventriculography. Utilize either a biplane

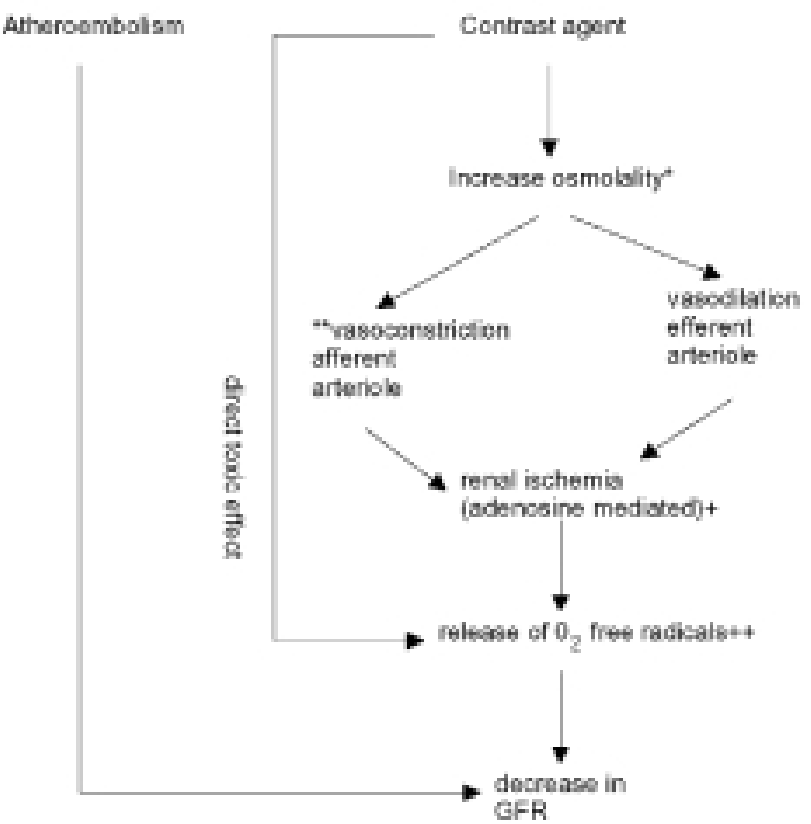

Figure 1. Mechanisms of contrast-induced nephropathy. Asterisk and crosses show the site of action of various agents. (GFR = glomerulate filtration rate; *low osmolar agents, hydration; **fenoldopam [use not universally accepted]; Calcium channel blockers [use not universally accepted]; +theophylline; $++\mathrm{N}$-acetylcysteine)

or a rotational cineangiography. ${ }^{10}$ Forced diuresis with mannitol or loop diuretics is not recommended because both may increase the likelihood of nephrotoxicty. ${ }^{11}$

\section{Acetylcysteine}

Acetylcysteine has been proven to be a very valuable tool in the prevention of contrast nephropathy. It acts as a scavenger of oxygen free radicals, increases the expression of nitric oxide synthase, which improves the blood supply, and has an antiapoptotic effect. All of these actions lead to amelioration of the renal effects of the dye. ${ }^{12}$ Tepel et al. randomized 83 patients to receive adequate hydration and either placebo or acetylcysteine in a dose of $600 \mathrm{mg}$ orally before and after performing computed tomography. The study revealed a significant effect in preventing contrast nephropathy in the acetylcysteine group. ${ }^{13}$ Since the Tepel et al. study, most, ${ }^{14-16}$ but not all ${ }^{17}$ other studies have confirmed their findings. The most recent of those studies was the paper by Kay et al. They conducted a prospective, randomized double-blind, placebocontrolled trial on 200 patients with mild to moderate renal dysfunction, undergoing coronary angiography. Serum creatinine clearance was lower in the acetylcysteine group $(P=0.006)$. In addition, the acetylcysteine group had increased creatinine clearance from $44.8 \mathrm{ml} / \mathrm{min}$ to $58.9 \mathrm{ml} / \mathrm{min} 12$ days after angiography $(P<0.001) .{ }^{14}$ The following are the key points of these trials.

- The results of most published studies were consistent revealing an improvement in creatinine of about $0.4 \mathrm{mg} / \mathrm{dl}$.

- The benefit of acetylcysteine is observed in patients, regardless of the original cause of the renal dysfunction.

- The benefit of acetylcysteine was observed in those patients with mild to moderate dysfunction, as well as patients with creatinine above $3.0 \mathrm{mg} / \mathrm{dl}$. 
- Acetylcysteine should be used in conjunction with the generally accepted guidelines of hydration and less dye use. When the amount of dye exceeded $140 \mathrm{ml}$ per procedure, the benefit was no longer observed.

- Patients with a higher risk of developing the disease, such as diabetic patients, received the most benefit from acetylcysteine.

Combining these facts with the low-risk and very low cost of the drug, acetylcysteine should be routinely administered to all patients with renal dysfunction undergoing contrast agent administration. In order for its benefit to be established in patients with more severe forms of renal dysfunction, or those requiring large volumes of dye, a large scale controlled study with a larger number of patients needs to be conducted. ${ }^{18}$

\section{Dopamine and Fenoldopam}

In order to improve renal blood flow, low dose dopamine was studied in controlled trials. It was found to be ineffective or only marginally beneficial. ${ }^{19,20}$ Dopamine is a non-selective agent and is not strong enough to counteract the contrast-induced afferent arteriolar vasoconstriction. ${ }^{21}$

Fenoldopam mesylate, a dopamine A1 receptor agonist, blocks the reduction in renal plasma flow. In a randomized study by Tumlin et al., 45 patients with chronic renal insufficiency were randomized to fenoldopam or placebo. ${ }^{22}$ The fenoldopam group had higher renal plasma flow and less rise in creatinine. There was no significant difference between the two groups in the contrast-induced nephropathy. The results are not surprising in light of the low power of the study. The only real criticism of this study is that, on average, the placebo group received more contrast dye compared to the active drug group. A large trial recently presented, but not yet in print, challenged the findings of Tumlin et al. and failed to show a benefit. ${ }^{23}$ Given the inconsistent benefits and the significant cost associated with the fenoldopam, it should not be utilized. Whether it will have a role in certain subgroups of patients or at different dosing schedules warrants further study. Similar to acetylcysteine the benefit was more marked in the patients with concomitant diabetes.

\section{Theophylline}

Huber et al. conducted a notable study to assess the role of theophylline in the prevention of contrast nephropathy. ${ }^{24}$ One hundred patients with baseline creatinine of approximately $2 \mathrm{mg} / \mathrm{dl}$ were randomized to $200 \mathrm{mg}$ theophylline or placebo. Patients received a relatively large volume of contrast (at least $100 \mathrm{ml}$ per patient). Theophylline resulted in preservation of kidney function and significantly decreased the incidence of contrast nephropathy. Contrast nephropathy was $4 \%$ in the theophylline group and $16 \%$ in the control group $(P=0.046)$.

The benefit is likely attributable to the antagonizing adenosine effect on the afferent arterioles causing vasodilation which will ameliorate ischemia. A small study by Abizaid et al. failed to show a benefit, which was most likely due to the low power of the study. ${ }^{25}$ Before the use of theophylline becomes a widely accepted practice, its benefit needs to be replicated in a large scale trial.

\section{Nifedipine}

It is known that calcium plays a role in the genesis of afferent arteriolar constriction. It is thus thought that a calcium channel blocker, nifedipine, may have a benefit in preventing contrast nephropathy. Controlled studies showed no benefit, and the drug should not be administered for this purpose. ${ }^{26}$

\section{Prophylactic hemodialysis}

An innovative idea is to provide hemodialysis to patients with renal dysfunction following angiography. Most, ${ }^{27-30}$ but not all, ${ }^{31}$ of the preliminary studies are encouraging. The key to its success is to shorten the time between dye administration and dialysis. Since dye effects start to occur 20 minutes post-administration, success hinges on starting the dialysis within this period. The negative study started dialysis within 280 minutes. In positive studies, dialysis started within approximately one hour of angiography. A large-scale controlled study is needed before a final recommendation can be established.

\section{CONCLUSION}

Renal insufficiency presents a challenge in patients with acute coronary syndromes. It is a common finding, and patients who have worsening kidney function following angiographic procedures will have a poor prognosis. ${ }^{32-34}$ This article is an attempt to lessen the risk of contrast nephropathy, thus improving the patient outcomes. An algorithm that helps clinicians achieve this goal is depicted in figure 2 .

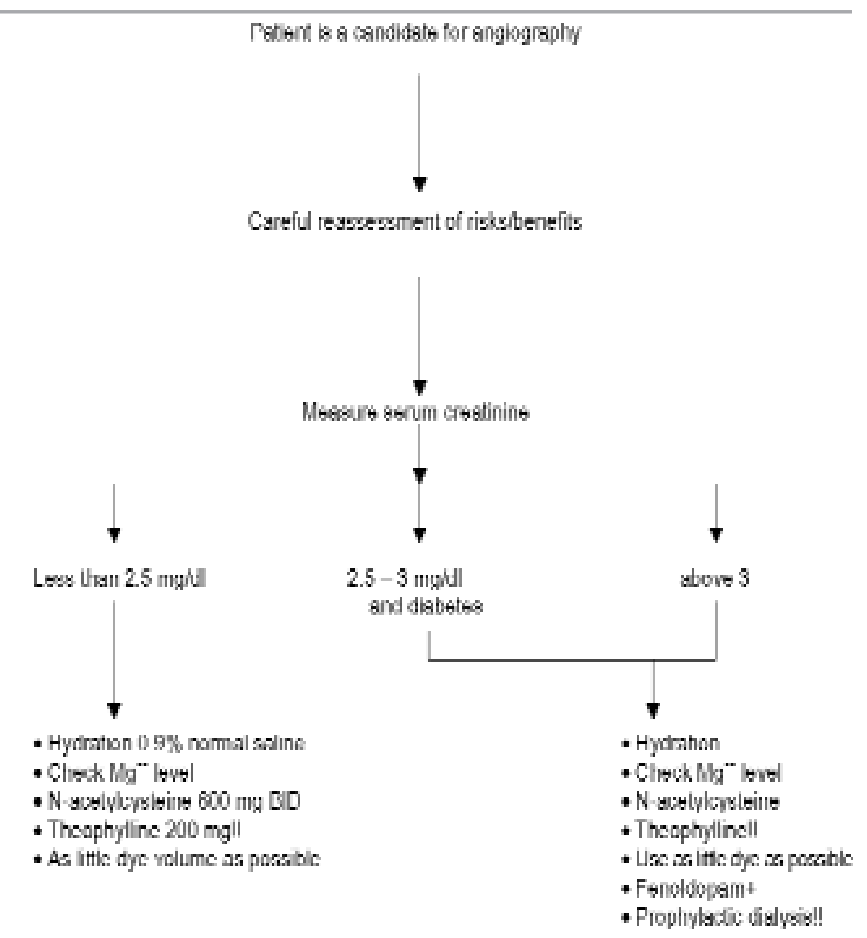

Figure 2. Suggested algorithm to decrease the incidence of contrast nephropathy prophylactic dialysis. (+Its role is still controversial, and not yet defined; !!Not universally accepted). 


\section{ACKNOWLEDGMENTS}

The authors wish to thank Marshfield Clinic Research Foundation for its support through the assistance of Linda Weis and Alice Stargardt in the preparation of this manuscript and Dr. Graig Eldred for his critique.

\section{REFERENCES}

1. Barrett BJ, Parfrey PS. Prevention of nephrotoxicity induced by radiocontrast agents. N Engl J Med 1994;331:1449-1450.

2. Conlon PJ, Little MA, Pieper K, Mark DB. Severity of renal vascular disease predicts mortality in patients undergoing coronary angiography. Kidney Int 2001;60:1490-1497.

3. Reis SE, Olson MB, Fried L, Reeser V, Mankad S, Pepine CJ, Kerensky R, Merz CN, Sharaf BL, Sopko G, Rogers WJ, Holubkov R. Mild renal insufficiency is associated with angiographic coronary artery disease in women. Circulation 2002;105:2826-2829.

4. Hemmelgarn BR, Ghali WA, Quan H, Brant R, Norris CM, Taub KJ, Knudtson ML. Poor long-term survival after coronary angiography in patients with renal insufficiency. Am J Kidney Dis 2001;37:64-72.

5. Vaitkus PT. Current status of prevention, diagnosis, and management of coronary artery disease in patients with kidney failure. Am Heart J 2000;139:1000-1008

6. Gruberg L, Waksman R, Ajani AE, Kim HS, White RL, Pinnow E, Deible R, Satler LF, Pichard AD, Kent KK, Lindsay J Jr. The effect of intracoronary radiation for the treatment of recurrent instent restenosis in patients with chronic renal failure. J Am Coll Cardiol 2001;38:1049-1053.

7. Katholi RE, Woods WT Jr, Taylor GJ, Deitrick CL, Womack KA, Katholi CR, McCann WP. Oxygen free radicals and contrast nephropathy. Am J Kidney Dis 1998;32:64-71.

8. Curhan GC. Prevention of contrast nephropathy. JAMA 2003;289:606-608.

9. Mueller C, Buerkle G, Buettner HJ, Petersen J, Perruchoud AP, Eriksson U, Marsch S, Roskamm H. Prevention of contrast media-associated nephropathy: randomized comparison of 2 hydration regimens in 1620 patients undergoing coronary angioplasty. Arch Intern Med 2002;162:329-336.

10. Kuon E, Niederst PN, Dahm JB. Usefulness of rotational spin for coronary angiography in patients with advanced renal insufficiency. Am J Cardiol 2002;90:369-373.

11. Stevens MA, McCullough PA, Tobin KJ, Speck JP, Westveer DC, Guido-Allen DA, Timmis GC, O'Neill WW. A prospective randomized trial of prevention measures in patients at high risk for contrast nephropathy: results of the P.R.I.N.C.E. Study. Prevention of Radiocontrast Induced Nephropathy Clinical Evaluation. J Am Coll Cardiol 1999;33:403-411.

12. Shyu KG, Cheng JJ, Kuan P. Acetylcysteine protects against acute renal damage in patients with abnormal renal function undergoing a coronary procedure. J Am Coll Cardiol 2002;40:1383-1388.

13. Tepel M, van der Giet M, Schwarzfeld C, Laufer U, Liermann D, Zidek W. Prevention of radiographic-contrast-agent-induced reductions in renal function by acetylcysteine. N Engl J Med 2000;343:180-184.

14. Kay J, Chow WH, Chan TM, Lo SK, Kwok OH, Yip A, Fan K, Lee $\mathrm{CH}$, Lam WF. Acetylcysteine for prevention of acute deterioration of renal function following elective coronary angiography and intervention: a randomized controlled trial JAMA 2003;289:553-558.

15. Diaz-Sandoval LJ, Kosowsky BD, Losordo DW. Acetylcysteine to prevent angiography-related renal tissue injury (the APART trial). Am J Cardiol 2002;89:356-358.

16. Briguori C, Manganelli F, Scarpato P, Elia PP, Golia B, Riviezzo G, Lepore S, Librera M, Villari B, Colombo A, Ricciardelli B. Acetylcysteine and contrast agent-associated nephrotoxicity. J Am Coll Cardiol 2002;40:298-303.
17. Durham JD, Caputo C, Dokko J, Zaharakis T, Pahlavan M, Keltz J, Dutka P, Marzo K, Maesaka JK, Fishbane S. A randomized controlled trial of $\mathrm{N}$-acetylcysteine to prevent contrast nephropathy in cardiac angiography. Kidney Int 2002;62:22022207.

18. Tepel M, Zidek W. Acetylcysteine and contrast media nephropathy. Curr Opin Nephrol Hypertens 2002;11:503-506.

19. Gare M, Haviv YS, Ben-Yehuda A, Rubinger D, Bdolah-Abram T, Fuchs S, Gat O, Popovtzer MM, Gotsman MS, Mosseri M. The renal effect of low-dose dopamine in high-risk patients undergoing coronary angiography. J Am Coll Cardiol 1999;34:1682-1688.

20. Hans SS, Hans BA, Dhillon R, Dmuchowski C, Glover J. Effect of dopamine on renal function after arteriography in patients with pre-existing renal insufficiency. Am Surg 1998;64:432-436.

21. Katholi RE, Taylor GJ. Renal effect of low-dose dopamine in highrisk patients undergoing coronary angiography. J Am Coll Cardiol 2000;36:306-307.

22. Tumlin JA, Wang A, Murray PT, Mathur VS. Fenoldopam mesylate blocks reductions in renal plasma flow after radiocontrast dye infusion: a pilot trial in the prevention of contrast nephropathy. Am Heart J 2002;143:894-903.

23. Stone GW, McCullough P, Tumlin J, Madyoon H, Murray P, Wang A, Chu AA, Schaer G, Stevens M, Wilensky RL, O’Neill WW, Lepor N. A prospective, randomized placebo-controlled multicenter trial evaluating fenoldopam mesylate for the prevention of contrast induced nephropathy: The CONTRAST Trial. J Am Coll Cardiol 2003;41:83A-84A.

24. Huber W, Ilgmann K, Page M, Hennig M, Schweigart U, Jeschke B, Lutilsky L, Weiss W, Salmhofer H, Classen M. Effect of theophylline on contrast material-nephropathy in patients with chronic renal insufficiency: controlled, randomized, doubleblinded study. Radiology 2002;223:772-779.

25. Abizaid AS, Clark CE, Mintz GS, Dosa S, Popma JJ, Pichard AD, Satler LF, Harvey M, Kent KM, Leon MB. Effects of dopamine and aminophylline on contrast-induced acute renal failure after coronary angioplasty in patients with preexisting renal insufficiency. Am J Cardiol 1999;83:260-263, A5.

26. Khoury Z, Schlicht JR, Como J, Karschner JK, Shapiro AP, Mook WJ, Weber RJ. The effect of prophylactic nifedipine on renal function in patients administered contrast media. Pharmacotherapy 1995;15:59-65.

27. Shinoda T, Hata T, Nakajima K, Yoshimoto H, Niwa A. Timecourse of iodine elimination by hemodialysis in patients with renal failure after angiography. Ther Apher 2002;6:437-442.

28. Huber W, Jeschke B, Kreymann B, Hennig M, Page M, Salmhofer H, Eckel F, Schmidt U, Umgelter A, Schweigart U, Classen M. Haemodialysis for the prevention of contrast-induced nephropathy: outcome of 31 patients with severely impaired renal function, comparison with patients at similar risk and review. Invest Radiol 2002;37:471-481.

29. Schindler R, Stahl C, Venz S, Ludat K, Krause W, Frei U. Removal of contrast media by different extracorporeal treatments. Nephrol Dial Transplant 2001;16:1471-1474

30. Moon SS, Back SE, Kurkus J, Nilsson-Ehle P. Hemodialysis for elimination of the nonionic contrast medium iohexol after angiography in patients with impaired renal function. Nephron 1995;70:430-437.

31. Vogt B, Ferrari P, Schonholzer C, Marti HP, Mohaupt M, Wiederkehr M, Cereghetti C, Serra A, Huynh-Do U, Uehlinger D, Frey FJ. Prophylactic hemodialysis after radiocontrast media in patients with renal insufficiency is potentially harmful. Am J Med 2001;111:692-698.

32. McCullough PA. Why is chronic kidney disease the "spoiler" for cardiovascular outcomes? J Am Coll Cardiol 2003;41:725-728.

33. Freeman RV, Mehta RH, Al Badr W, Cooper JV, Kline-Rogers E, Eagle KA. Influence of concurrent renal dysfunction on outcomes of patients with acute coronary syndromes and implications of the use of glycoprotein IIb/IIIa inhibitors. J Am Coll Cardiol 2003;41:718-724.

34. Safirstein R, Andrade L, Vieira JM. Acetylcysteine and nephrotoxic effects of radiographic contrast agents-a new use for an old drug. N Engl J Med 2000;343:210-212. 